\title{
Synthesis and Properties of the First Representatives of Fluorenonoazacrownophanes and Fluorenonocryptand
}

\author{
Alexander V. Lobach, Irene S. Yakovenko and Nikolay G. Lukyanenko@ \\ A.V. Bogatsky Physico-Chemical Institute, National Academy of Sciences of Ukraine, Odessa, 65080, Ukraine \\ ${ }^{\circledR}$ Corresponding author E-mail: ngl@farlep.net
}

\begin{abstract}
The reaction of bistosylates or diiodides of 2,7-bis[2-(2-hydroxyethoxy)ethoxy]- or 2,7-bis\{2-[2-(2-hydroxyethoxy) ethoxy]ethoxy?fluorenone with toluenesulfonamide in DMF or with benzylamine in $\mathrm{CH}_{3} \mathrm{CN}$ under high dilution conditions at $80^{\circ} \mathrm{C}$ in the presence of potassium carbonate resulted in the formation of the first representatives of fluorenonoazacrownophanes and bis(fluorenono)diazacrownophanes as the products of [1+1] and [2+2] condensation

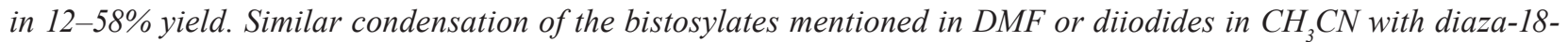
crown-6 afforded the corresponding fluorenonocryptand in the yields of 18 and $35 \%$, respectively.
\end{abstract}

Keywords: Cyclophane, crownophane, azacrownophane, fluorenone.

\section{Синтез и свойства первых представителей флуореноноазакраунофанов и флуоренонокриптанда}

\author{
А.В. Лобач, И.С. Яковенко, Н.Г. Лукьяненко ${ }^{\circledR}$ \\ Физико-химический институт имени А.В. Богатского Нацииональной академии наук Украины, Одесса, 65080, Украина \\ ${ }^{\circledR}$ E-mail:ngl@farlep.net
}

\begin{abstract}
Конденсацией дитозил- или дииодпроизводных 2,7- бис[2-(2-гидроксиэтокси)этокси]- и 2,7-бис\{2-[2-(2гидроксиэтокси)этоксиЈэтокси фрлуоренонов с п-толилсульфониламидом в ДМФА или с бензиламином в ацетонитриле в условиях высокого разбавления в присутствии безводного карбоната калия при $80^{\circ} \mathrm{C}$ с выходом 12 - 58\% получены первые представители флуореноноазакраунофанов и бис(флуореноно)диазакраунофанов, являюшиеся продуктами реакции по схеме [1+1] и [2+2]. Аналогичная конденсация указанных дитозилатов в ДМФА или дииодидов в ацетонитриле с диаза-18-краун-6 приводит к соответствующему флуоренонокриптанду с выходом 18 и 35\%, соответственно.
\end{abstract}

Ключевые слова: Циклофан, краунофан, азакраунофан, флуоренон.

\section{Введение}

Конструирование, синтез и использование разнообразных макроциклических рецепторов, способных к селективному распознаванию ионов металлов, анионов и органических молекул являются одной из основных задач химии гость-хозяин. В ряду таких рецепторов особое внимание привлекают краунофаны, в которых большие ароматические фрагменты соединены полиоксаэтиленовыми цепочками. Краунофаны удачно сочетают свойства классических краун-эфиров и циклофанов. Такой симбиоз свойств делает их отличными рецепторами как ионных, так и нейтральных соединений. ${ }^{[1-4]}$

Структура, стабильность и селективность образования молекулярных комплексов и супрамолекулярных систем определяется широким набором нековалентных взаимодействий между молекулами «хозяина» и «го- стя». ${ }^{[5]}$ Изменение силы и природы таких взаимодействий за счет введения в молекулу макроциклического рецептора рационально подобранных молекулярных фрагментов и функциональных групп позволяет достаточно эффективно управлять его комплексообразующими свойствами. В частности, введение атомов азота в макроциклический остов молекулы дает в руки исследователей дополнительный инструмент регулирования комплексообразующих свойств краунофанов.

В ряду известных азациклофанов достаточно широко представлены соединения с фрагментами гидрохинона, нафталина, бифенила, антрацена и некоторых других конденсированных ароматических и гетероароматических систем. ${ }^{[6,7]}$ Однако, до начала наших исследований совершенно не были изучены азакраунофаны с фрагментами флуоренона. В то же время с точки зрения химии гость-хозяин фрагмент 
флуоренона обладает рядом полезных свойств: большая поляризованная ароматическая система должна эффективно участвовать в $\pi$-катионных ${ }^{[8-12]}$ и $\pi-\pi$ стекинг взаимодействиях с молекулой гостя, ${ }^{[13-16]}$ а также в образовании водородных связей. ${ }^{[17-19]}$ В продолжение наших исследований флуоренонокраунофанов, ${ }^{[20-26]}$ в настоящем сообщении мы описываем синтез и свойства первых представителей флуореноноазакраунофанов.

\section{Экспериментальная часть}

Спектры ${ }^{1} \mathrm{H}$ ЯМР растворов веществ в $\mathrm{CDCl}_{3}$ регистрировали на приборе Varian VXR-300 с рабочей частотой 300 МГц, внутренний стандарт - ТМС. Масс-спектры получены на масс-спектрометре MX-1321 с прямым вводом образца в ионный источник при энергии ионизации 70 Эв, температура ионизационной камеры $200{ }^{\circ} \mathrm{C}$, FAB масс-спектры - на массспектрометре VG 7070EQ (Xе, 8 кB) в матрице 3-нитробензилового спирта. УФ спектры записаны на спектрофотометре Specord M-40. Температуры плавления измерены в открытых капиллярах и не исправлены. Элементный анализ проводили на CHNS анализаторе EuroVector EA3000. Чистоту всех синтезированных веществ контролировали методом тонкослойной хроматографии на стеклянных пластинах с закрепленным слоем нейтрального оксида алюминия (L 5/40), проявляли парами иода. Для препаративной жидкостной хроматографии использовали стеклянные колонки с нейтральным оксидом алюминия (L 40/250), элюент - хлороформ-бензол-метанол, $8: 3: 0,5$. 2,7-Дигидрокси-9H-флуорен-9-он ${ }^{[27]}$ и дитозилаты $\mathbf{1 a}, \boldsymbol{\sigma}^{[22]}$ получали, как описано ранее. 1,5-Дихлор-3-оксапентан и 1,8-дихлор-3,6-диоксаоктан и диаза-18-краун-6 коммерчески доступны.

\section{Синтез}

Общая методика получения дииодидов, 16,2. Смесь 8,48 г (40 ммоль) 2,7-дигидрокси-9Н-флуорен-9-она, 25,44 г (240 ммоль) свежепрокаленного $\mathrm{Na}_{2} \mathrm{CO}_{3}$ и 72 г (480 ммоль) свежепрокаленного $\mathrm{NaI}$ в 600 мл безводного ДМФА перемешивали при $80^{\circ} \mathrm{C}$ в атмосфере аргона 0,5 ч, прибавляли 34,32 г (240 ммоль) 1,5-дихлор-3-оксапентана или 44,88 г (240 ммоль) 1,8-дихлор-3,6-диоксаоктана и продолжали перемешивание при той же температуре еще 40 ч. Реакционную смесь фильтровали, фильтрат упаривали в вакууме. Остаток промывали гексаном (3×50 мл) и растворяли в 150 мл хлороформа. Полученный раствор промывали 10 \%-ным водным раствором тиосульфата натрия $(3 \times 30$ мл) и водой $(2 \times 50$ мл), сушили безводным $\mathrm{MgSO}_{4}$, упаривали в вакууме. Остаток очищали хроматографией на колонке.

2,7-Бис[2-(2-иодоэтокси)этокси]-9Н-флуорен-9-он, 16. Оранжевые кристаллы, выход 14,59 г (60\%), т. пл. 121-122 ${ }^{\circ} \mathrm{C}$ из 2-пропанола. Найдено, \%: С 41,49, Н 3,45. C $\mathrm{H}_{22} \mathrm{I}_{2} \mathrm{O}_{5}$. Вычислено, \%: С 41,47, Н 3,65. m/z (ЭИ) $I_{\text {отн }}, \%: 608\left[\mathrm{M}^{+}\right](87) .{ }^{1} \mathrm{H}$

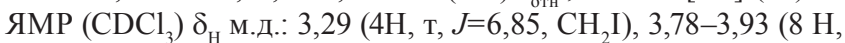
м, $\left.\mathrm{CH}_{2} \mathrm{O}\right), 4,13-4,22\left(4 \mathrm{H}, \mathrm{м}, \mathrm{CH}_{2} \mathrm{OAr}\right), 6,98$ (2H, дд, $J=8,09$, 2,19, $\mathrm{H}^{3}, \mathrm{H}^{6}$-Flu), 7,17 (2H, д, $J=2,19, \mathrm{H}^{1}, \mathrm{H}^{8}$-Flu), 7,29 (2H, д, $J=$ 8,09, $\mathrm{H}^{4}, \mathrm{H}^{5}$-Flu). ЭСП $\left(\mathrm{CH}_{3} \mathrm{CN}\right), \lambda_{\text {масс }}$., нм $(\lg \varepsilon): 270(4,91), 298$ $(3,91), 313(3,86), 452(2,74)$.

2,7-Бис\{2-[2-(2-иодоэтокси)этокси]этокси\}-9H-флуорен9-он, 12. Оранжевые кристаллы, выход 15,31 г (55\%), т. пл. $49-50^{\circ} \mathrm{C}$ из 2-пропанола. Найдено, \%: С 43,29, Н 4.31. $\mathrm{C}_{25} \mathrm{H}_{30} \mathrm{I}_{2} \mathrm{O}_{7}$.

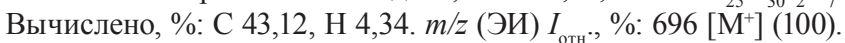
${ }^{1} \mathrm{H}$ ЯMP $\left(\mathrm{CDCl}_{3}\right), \delta_{\mathrm{H}}$ м.д.: 3,27 (4H, т, $\left.J=6,85, \mathrm{CH}_{2} \mathrm{I}\right), 3,66-3,82$ $\left(12 \mathrm{H}, \mathrm{м}, \mathrm{CH}_{2} \mathrm{O}\right), 3,88\left(4 \mathrm{H}, \mathrm{T}, J=4,67, \mathrm{CH}_{2} \mathrm{O}\right), 4,17$ (4 H, т, $J=4.67$, $\mathrm{CH}_{2} \mathrm{OAr}$ ), 6,97 (2H, дд, $J=8,09,2,19, \mathrm{H}^{3}, \mathrm{H}^{6}$-Flu), 7,17 (2H, д, $J=2,19$, $\mathrm{H}^{1}, \mathrm{H}^{8}$-Flu), 7,28 (2H, д, $J=8.09, \mathrm{H}^{4}, \mathrm{H}^{5}$-Flu). ЭСП $\left(\mathrm{CH}_{3} \mathrm{CN}\right), \lambda$ нм (lg ع): $271(4,93), 301(3,86), 313(3,84), 471(2,48)$.
Общзая методика получения флуореноноазакраунофанов, 2a, 3a,б. Смесь 3,55 г (5,1 ммоль) дитозилата 1a или 4,00 г (5,1 ммоль) дитозилата 1б, 0,87 г (5,1ммоль) $n$-толилсульфониламида и 2,82 г (20,4 ммоль) свежепрокаленного $\mathrm{K}_{2} \mathrm{CO}_{3}$ в 500 мл безводного ДМФА перемешивали при 80 ${ }^{\circ} \mathrm{C}$ в атмосфере аргона 60 ч. Охлаждали, ДМФА упаривали в вакууме, твердый остаток растворяли в 150 мл горячего хлороформа, отфильтровывали нерастворившуюся массу, фильтрат упаривали в вакууме. Остаток очищали хроматографией на колонке.

17-[(4-Метилфенил)сульфонил]-8,11,14,20,23,26гексаокса-17-азатетраиикло[25.3.1.1.1,7.04,30]дотриаконта1(31),3(32),4,6,27,29-гексаен-2-он, $2 \boldsymbol{a}$. Коричневые кристаллы, выход 0,37 г (12\%), т. пл. $155-156^{\circ} \mathrm{C}$ из 2-пропанола. Найдено, \%: С 62,75, Н 6,20, N 2,12, S 5,19. С $\mathrm{H}_{37} \mathrm{NO}_{9} \mathrm{~S}$. Вычислено, \%:

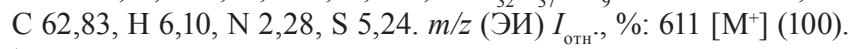
${ }^{1} \mathrm{H}$ ЯМР $\left(\mathrm{CDCl}_{3}\right), \delta_{\mathrm{H}}$ м.д.: 2,42 (3H, с, Me), 3,28 (4H, т, $J=7,47$, $\left.\mathrm{CH}_{2} \mathrm{~N}\right), 3,43-3,52\left(12 \mathrm{H}, \mathrm{\text {м }}, \mathrm{CH}_{2} \mathrm{O}\right), 3,75\left(4 \mathrm{H}, \mathrm{\text {т }}, J=7,05, \mathrm{CH}_{2} \mathrm{O}\right), 4,31$ (4H, т, $\left.J=7,05 \mathrm{CH}_{2} \mathrm{O}\right), 6,95$ (2H, дд, $\left.J=8.09,2.49, \mathrm{H}^{3}, \mathrm{H}^{6}-\mathrm{Flu}\right), 7,19$ ( $2 \mathrm{H}$, д, $\left.J=8,09, \mathrm{H}^{4}, \mathrm{H}^{5}-\mathrm{Flu}\right), 7,27$ (2H, д, $\left.J=8,09, \mathrm{Ar}\right), 7,54$ (2H, д, $\left.J=2.49, \mathrm{H}^{1}, \mathrm{H}^{8}-\mathrm{Flu}\right), 7,69(2 \mathrm{H}$, д, $J=8,09 \mathrm{Ar})$. ЭСП $\left(\mathrm{CH}_{3} \mathrm{CN}\right), \lambda_{\text {макс }}$, нм (lg ع): 272 (3,86), $303(2,80), 314(2,76), 471(1,47)$.

14,38-Бис[(4-метилфенил)сульфонил]-8,11,17,20,32,35, 41,44-октаокса-14,38-диазагептачикло[43.3.1.1.1,7.121,25. $1^{27,31}$ $\left.0^{4,48} \cdot 0^{24,28}\right]$ допентаконта-1(49), 3(52), 4, 6, 21(51), 22, 24,27(50), 28,30,45,47-додекаен-2,26-дион, 3a. Оранжевые кристаллы, выход 1,65 г (31\%), т. пл. $200^{\circ} \mathrm{C}$ из бензола. Найдено, \%: С 64,10 , Н 5,35, N 2,60, S 6,14. $\mathrm{C}_{56} \mathrm{H}_{58} \mathrm{~N}_{2} \mathrm{O}_{14} \mathrm{~S}_{2}$. Вычислено, \%: С

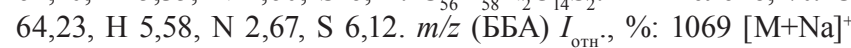
(24), $1047[\mathrm{M}+\mathrm{H}]^{+}(100) .{ }^{1} \mathrm{H}$ ЯМР $\left(\mathrm{CDCl}_{3}\right), \delta_{\mathrm{H}}$ м.д.: $2,43(6 \mathrm{H}, \mathrm{c}$, $\mathrm{Me}), 3,42\left(8 \mathrm{H}, \mathrm{T}, J=5.46, \mathrm{CH}_{2} \mathrm{~N}\right), 3,66-3,81\left(16 \mathrm{H}, \mathrm{м}, \mathrm{CH}_{2} \mathrm{O}\right), 3,93$ $\left(8 \mathrm{H}\right.$, т, $\left.J=4,50, \mathrm{CH}_{2} \mathrm{O}\right), 6,72$ (4H, дд, $\left.J=8,09,2,49, \mathrm{H}^{3}, \mathrm{H}^{6}-\mathrm{Flu}\right)$, 6,84 (4H, д, $\left.J=2,49, \mathrm{H}^{1}, \mathrm{H}^{8}-\mathrm{Flu}\right), 6,98$ д (4H, $\left.J=8,09, \mathrm{Ar}\right), 7,20(4 \mathrm{H}$, д, $\left.J=8,09, \mathrm{H}^{4}, \mathrm{H}^{5}-\mathrm{Flu}\right), 7,72(4 \mathrm{H}$, д, $J=8,09, \mathrm{Ar})$. ЭСП $\left(\mathrm{CH}_{3} \mathrm{CN}\right)$, $\lambda_{\text {макс }}$ нм ( $\left.\lg \varepsilon\right): 263(4,73), 474(3,13)$.

17,47-Бис[(4-метилфенил)сульфонил]-8,11,14,20,23,26,38, 41,44,50, 53,56-додекаокса-17,47-диазагептаиикло $\left[55.3 \cdot 1 \cdot 1^{3,7} \cdot 1^{27,31} \cdot 1^{33,37} \cdot 0^{4,60} \cdot 0^{30,34}\right]$ те тр рагексаконта1(61),3(64), 4, 6, 27(63), 28,30,33(62), 34,36,57,59-додекаен-2,32дион, 3б. Оранжевые кристаллы, выход 1,50 г (24\%), т. пл. $137-138^{\circ} \mathrm{C}$ из бензола. Найдено, \%: С 63,01, Н 6,28, N 2,55, S 5,20. $\mathrm{C}_{64} \mathrm{H}_{74} \mathrm{~N}_{2} \mathrm{O}_{18} \mathrm{~S}_{2}$. Вычислено, \%: С 62,83, Н 6.10, N 2.28; S 5.24. $\mathrm{m} / \mathrm{z}\left(\right.$ ББА) $I_{\text {отн }}, \%: 1245[\mathrm{M}+\mathrm{Na}]^{+}(41), 1223[\mathrm{M}+\mathrm{H}]^{+}(100)$. ${ }^{1} \mathrm{H}$ ЯМР $\left(\mathrm{CDCl}_{3}\right), \delta_{\mathrm{H}}$ м.д.: 2,39 (6H, c, Me), 3,38 (8H, т, J=5,90 $\left.\mathrm{CH}_{2} \mathrm{~N}\right), 3,54-3,68\left(24 \mathrm{H}, \mathrm{м}, \mathrm{CH}_{2} \mathrm{O}\right), 3,78\left(8 \mathrm{H}, \mathrm{T}, J=4.50, \mathrm{CH}_{2} \mathrm{O}\right)$, 4,08 ( $\left.8 \mathrm{H}, \mathrm{T}, J=4.50 \mathrm{CH}_{2} \mathrm{O}\right), 6,86\left(4 \mathrm{H}\right.$, дД, $\left.J=8.09,2.18, \mathrm{H}^{3}, \mathrm{H}^{6}-\mathrm{Flu}\right)$, $7,05\left(4 \mathrm{H}\right.$, д, $\left.J=2,18, \mathrm{H}^{1}, \mathrm{H}^{8}-\mathrm{Flu}\right), 7,16(4 \mathrm{H}$, д, $J=8.09$, Ar), 7,25 д (4H, $J=8,09, \mathrm{H}^{4}, \mathrm{H}^{5}$-Flu), 7,70 (4H, д, $J=8.09$ Ar). 1067 (27). ЭСП $\left(\mathrm{CH}_{3} \mathrm{CN}\right), \lambda_{\text {макс }}$, $\mathrm{HM}(\lg \varepsilon): 263(5,05), 473(3,46)$.

Общая методика получения флуореноноазакраунофанов, 2б, 3в,г. Суспензию 3,15 г (22,8 ммоль) свежепрокаленного $\mathrm{K}_{2} \mathrm{CO}_{3}$ в 300 мл безводного ацетонитрила нагревали при перемешивании в атмосфере аргона до $50-60^{\circ} \mathrm{C}$ и прибавляли в течение 5 ч смесь 3,47 г (5,7 ммоль) дииодида 1в или 4,00 г (5,7ммоль) дииодида 1г и 0,61 г (5,7 ммоль) бензиламина в 200 мл безводного ацетонитрила. По окончании прибавления температуру повышали до $80^{\circ} \mathrm{C}$ и продолжали перемешивание еще 25 ч. После охлаждения реакционную смесь фильтровали, осадок на фильтре промывали хлороформом (3×30 мл), фильтрат упаривали в вакууме. Твердый остаток растворяли в 150 мл хлороформа, отфильтровывали нерастворившуюся массу, фильтрат промывали 10\%-ным водным раствором тиосульфата натрия $(3 \times 30$ мл) и водой $(2 \times 50$ мл). Сушили безводным $\mathrm{MgSO}_{4}$ и упаривали в вакууме. Остаток очищали хроматографией на колонке.

17-Бензил-8, 11,14,20,23,26-гексаокса-17-азатетрацикло $\left[25.3 \cdot 1 \cdot 1^{3,7} \cdot 0^{4,30}\right]$ дотриаконта-1(31),3(32),4,6,27,29-гексаен-2-он, 2б. Коричневые кристаллы, выход 0,69 г (22\%), т. пл. $83-84^{\circ} \mathrm{C}$ 
из 2-пропанола. Найдено, \%: С 70,35, Н 6,70, N 2.71. $\mathrm{C}_{32} \mathrm{H}_{37} \mathrm{NO}_{7}$. Вычислено, \%: С 70,18, Н 6,81, N 2,55. m/z (ББА) $I_{\text {отн. } \%: 548}$ $[\mathrm{M}+\mathrm{H}]^{+}(100) .{ }^{1} \mathrm{H}$ ЯMP $\left(\mathrm{CDCl}_{3}\right), \delta_{\mathrm{H}}$ м.д.: 3,38-3,47 $\left(6 \mathrm{H}, \mathrm{M}, \mathrm{CH}_{2} \mathrm{~N}\right)$, $3,49-3,58\left(12 \mathrm{H}, \mathrm{м}, \mathrm{CH}_{2} \mathrm{O}\right), 3,78\left(4 \mathrm{H}, \mathrm{T}, J=4,21, \mathrm{CH}_{2} \mathrm{O}\right), 4,33(4 \mathrm{H}, \mathrm{T}$, $\left.J=4.21, \mathrm{CH}_{2} \mathrm{O}\right), 6,99\left(2 \mathrm{H}\right.$, дд, $\left.J=8,09,2,49, \mathrm{H}^{3}, \mathrm{H}^{6}-\mathrm{Flu}\right), 7.20-7.30(7 \mathrm{H}$, м, $\mathrm{H}^{4}, \mathrm{H}^{5}$-Flu, Ar), 7,46 (2H, д, $J=2,49, \mathrm{H}^{1}, \mathrm{H}^{8}$-Flu). ЭСП $\left(\mathrm{CH}_{3} \mathrm{CN}\right)$, $\lambda_{\text {макс }}$, нм $(\lg \varepsilon): 272(4,85), 303(3,78), 314(3,74), 472(2,44)$.

14,38-Дибензил-8,11,17,20,32,35,41,44-октаокса-14,38диазагептаиикло[43.3.1.1 $\left.1^{3,7} \cdot 1^{21,25} \cdot 1^{27,31} \cdot 0^{4,48} \cdot 0^{24,28}\right]$ допентаконта1(49), 3(52), 4, 6, 21(51), 22, 24,27(50), 28,30,45,47-додекаен-2,26дион, 3в. Оранжевые кристаллы, выход 3,04 г (58\%), т. пл. $205^{\circ} \mathrm{C}$ из бензола. Найдено, \%: С 73,22, Н 6,46, N 2.80. $\mathrm{C}_{56} \mathrm{H}_{58} \mathrm{~N}_{2} \mathrm{O}_{10}$.

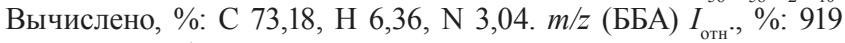
$[\mathrm{M}+\mathrm{H}]^{+}(100) .{ }^{~}{ }^{\mathrm{H}}$ ЯMP $\left(\mathrm{CDCl}_{3}\right), \delta_{\mathrm{H}}$ м.д.: $2,74-2,97\left(12 \mathrm{H}, \mathrm{M}, \mathrm{CH}_{2} \mathrm{~N}\right)$, 3,61-3,87 (16H, м, $\left.\mathrm{CH}_{2} \mathrm{O}\right), 3,89-4,05$ ( $8 \mathrm{H}$, м, $\left.\mathrm{CH}_{2} \mathrm{O}\right), 6,77$ (4H, дд, $J=8,09,2,49, \mathrm{H}^{3}, \mathrm{H}^{6}-\mathrm{Flu}$ ), 6,89 (4H, д, $\left.J=2.49 \mathrm{H}^{1}, \mathrm{H}^{8}-\mathrm{Flu}\right), 6,99$ (4Н, д, $\left.J=8,09, \mathrm{H}^{4}, \mathrm{H}^{5}-\mathrm{Flu}\right), 7,20-7,45(10 \mathrm{H}, \mathrm{M}, \mathrm{Ar})$. ЭСП $\left(\mathrm{CH}_{3} \mathrm{CN}\right), \lambda_{\text {макс }}$, НМ (lg ع): 263 (5,06), 301 (4,05), $314(4,02), 474$ (2,73).

17,47-Дибензил-8, 11,14, 20,23,26,38,41,44,50,53,56додекаокса-17,47-диазагептацикло[55.3.1.1.1,7.127,31.133,37. $0^{4,60} \cdot 0^{30,34} \mathrm{~J}$ тетрагексаконта-1(61), 3(64), 4,6,27(63), 28,30,33(62),34,36,57,59-додекаен-2,32-дион, 32. Оранжевые кристаллы, выход 2,89 г (46\%), т. пл. $145^{\circ} \mathrm{C}$ из бензола. Найдено, \%: С 70,20, Н 6,67, N 2,46. $\mathrm{C}_{64} \mathrm{H}_{74} \mathrm{~N}_{2} \mathrm{O}_{14}$. Вычислено, \%: C 70,18, H 6,81, N 2,55. $\mathrm{m} / \mathrm{z}$ (ББА) $I_{\text {оти. }}^{4} \%: 1095[\mathrm{M}+\mathrm{H}]^{+}(100)$. ${ }^{1} \mathrm{H}$ ЯMP $\left(\mathrm{CDCl}_{3}\right), \delta_{\mathrm{H}}$ м.д.: 3,58-3,74 $\left(36 \mathrm{H}, \mathrm{M}, \mathrm{CH}_{2} \mathrm{~N}, \mathrm{CH}_{2} \mathrm{O}\right), 3,82$ ( $\left.8 \mathrm{H}, \mathrm{T}, J=4.53, \mathrm{CH}_{2} \mathrm{O}\right), 4,05\left(8 \mathrm{H}, \mathrm{T}, J=4,25, \mathrm{CH}_{2} \mathrm{O}\right), 6,82(4 \mathrm{H}$, дд, $J=8,09,2.49, \mathrm{H}^{3}, \mathrm{H}^{6}$-Flu), 6,99 (4H, д, $\left.J=2.49, \mathrm{H}^{1}, \mathrm{H}^{8}-\mathrm{Flu}\right), 7,09$ (4H, д, $J=8.09, \mathrm{H}^{1}, \mathrm{H}^{8}$-Flu $), 7,22-7,42$ (10H, м, $\left.\mathrm{Ar}\right)$. ЭСП $\left(\mathrm{CH}_{3} \mathrm{CN}\right), \lambda_{\text {макс' }}$, нм (lg ع): $271(5,04), 300(3,95), 313(3,91), 470(2,71)$.

$4,7,10,22,25,28,34,37,42,45$ - Декаокса-1, 31 диазапентаиикло[29.8.8.1 $\left.1^{11,15} \cdot 1^{17,21} \cdot 0^{14,18}\right]$ нонатетраконта- 11(49),12,14,17(48),18,20-гексаен-16-он, 4. Метод А. Получали аналогично флуореноноазакраунофанам 2а, 3a, $\mathbf{0}$ из 4,00 г (5,1 ммоль) дитозилата 1б, 1,34 г (5,1 ммоль) диаза-18-краун-6 и 2,82 г (20,4 ммоль) свежепрокаленного $\mathrm{K}_{2} \mathrm{CO}_{3}$. Коричневые кристаллы, выход 0,65 г (18\%), т. пл. $73-74{ }^{\circ} \mathrm{C}$ из 2-пропанола. Вычислено, \%: С 63,23, Н 7,74, N 3,98. $\mathrm{C}_{37} \mathrm{H}_{54} \mathrm{~N}_{2} \mathrm{O}_{11}$. Найдено, \%:

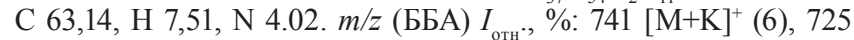
$[\mathrm{M}+\mathrm{Na}]^{+}(46), 703[\mathrm{M}+\mathrm{H}]^{+}(100) .{ }^{1} \mathrm{H}$ ЯMP $\left(\mathrm{CDCl}_{3}\right), \delta_{\mathrm{H}}$ м.д.: 2,73$2,87\left(12 \mathrm{H}, \mathrm{м}, \mathrm{CH}_{2} \mathrm{~N}\right), 3,52-3,65\left(16 \mathrm{H}, \mathrm{м}, \mathrm{CH}_{2} \mathrm{O}\right), 3,67-3,78(12 \mathrm{H}$, м, $\left.\mathrm{CH}_{2} \mathrm{O}\right), 3,81-3,93\left(4 \mathrm{H}, \mathrm{м}, \mathrm{CH}_{2} \mathrm{O}\right), 4,12-4.22\left(4 \mathrm{H}, \mathrm{м}, \mathrm{CH}_{2} \mathrm{O}\right), 6,97$ (2H, дд, $J=8,09,2,49, \mathrm{H}^{3}, \mathrm{H}^{6}$-Flu), 7,16 (2H, д, $\left.J=2,49, \mathrm{H}^{1}, \mathrm{H}^{8}-\mathrm{Flu}\right)$, $7,28\left(2 \mathrm{H}\right.$, д, $\left.J=8,09, \mathrm{H}^{4}, \mathrm{H}^{5}-\mathrm{Flu}\right)$. ЭСП $\left(\mathrm{CH}_{3} \mathrm{CN}\right), \lambda_{\text {мес }}$ нм $(\lg \varepsilon)$ : $271(4,80), 301(3,90), 313(3,80), 463(2,41)$. Метод Б. Получали аналогично флуореноноазакраунофанам 2б, 3в,г из 4,00 г (5,7 ммоль) дииодида 1г, 1,49 г (5,7 ммоль) диаза-18-краун-6 и 3,15 г (22,8 ммоль) свежепрокаленного К $\mathrm{CO}_{3}$. Выход 1,40 г (35\%).

\section{Результаты и обсуждение}

Конденсация дитозилатов 1a,б с $n$-толилсульфониламидом в условиях большого разбавления в ДМФА в присутствии безводного карбоната калия при $80^{\circ} \mathrm{C}$ после обработки реакционной смеси и хроматографической очистки на нейтральном оксиде алюминия приводит к флуореноноазакраунофану 2а и бис(флуореноно) диазакраунофанам 3a,б, которые являются продуктами взаимодействия по схеме [1+1] и [2+2]. Аналогичное взаимодействие дииодидов 1в,г с бензиламином в ацетонитриле дает $N$-Bn-замещенные флуореноноазакраунофан 2 б и бис(флуореноно)диазакраунофаны 3в,г (Схема 1).

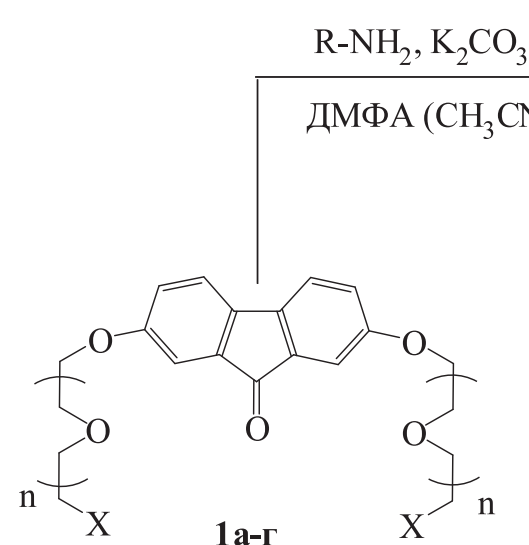

$\mathrm{X}=\mathrm{OTs}, \mathrm{n}=1(\mathbf{a}), \mathrm{n}=2(\mathbf{6})$;

$\mathrm{X}=\mathrm{I}, \mathrm{n}=1(\mathbf{B}), \mathrm{n}=2(\mathbf{\Gamma})$

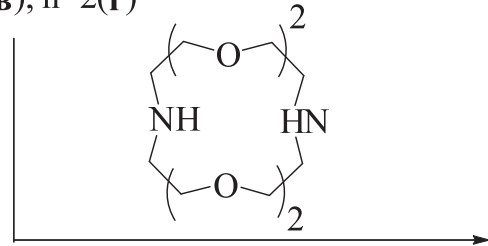

$\mathrm{K}_{2} \mathrm{CO}_{3}$, ДМФА $\left(\mathrm{CH}_{3} \mathrm{CN}\right)$<smiles>[R]N(CC([2H])(C)COCC(C)(C)C)CC([2H])(C)COc1ccc2c(c1)C(=O)c1cc(OCC(C)(C)C)ccc1-2</smiles>

2a, 0

$\mathrm{R}=\mathrm{Ts}(\mathbf{a}), \mathrm{R}=\mathrm{Bn}(\boldsymbol{\mathbf { \sigma }})$

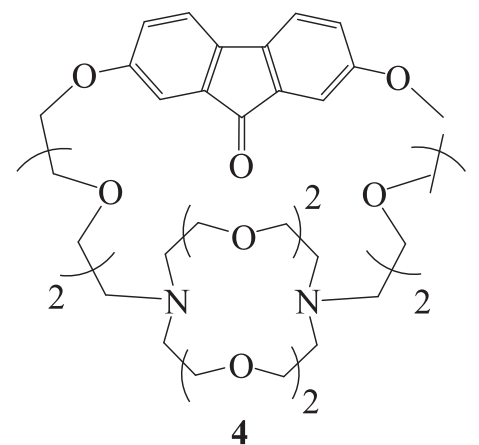

Схема 1. Синтез флуореноноазакраунофанов 2а,б, 3а-г и флуоренонокриптанда 4. 
Попытки выделения из реакционной смеси флуореноноазакраунофанов в реакциях по схеме $[1+1]$ с использованием дитозилата 1а и дииодида 1в не привели к положительному результату. Вероятно, это связано с невозможностью образования циклической структуры из-за недостаточной длины олигоэтиленгликолевых цепочек. Это предположение подтверждается анализом молекулярных моделей СРК (Corey-Pauling-Koltun) и результатами компьютерного моделирования.

Флуоренонокриптанд 4 получен конденсацией диаза-18-краун-6 с дитозилатом 16 в ДМФА или дииодидом 1г в ацетонитриле в условиях большого разбавления в присутствии безводного карбоната калия при $80^{\circ} \mathrm{C}$ с последующим выделением и очисткой продукта на колонке с нейтральным оксидом алюминия. Выход криптанда 4 при взаимодействии дитозилата $\mathbf{1 6}$ с диаза18-краун-6 в ДМФА был практически в два раза ниже, чем при конденсации дииодида 1г с диаза-18-краун-6 в ацетонитриле. При этом продолжительность реакции в первом случае составляла 60 ч, а во втором - 30 ч.

В спектрах ${ }^{1} \mathrm{H}$ ЯМР флуореноноазакраунофанов 2a,б, 3a-г и флуоренонокриптанда $\mathbf{4}$ наблюдается типичный для азакраун-эфиров набор сигналов $\mathrm{NCH}_{2}$ групп в области 2,53-3,47 м.д. и $\mathrm{OCH}_{2}$-групп в области 3,49-4,33 м.д. Флуореноновые протоны представлены характерным набором сигналов в виде двух дублетов и дублета дублетов в области 6,70-7,72 м.д. Присутствуют также сигналы всех других имеющихся групп протонов, что подтверждает строение полученных соединений. В масс-спектрах всех изученных азакраунофанов присутствуют пики соответствующих молекулярных ионов. В электронных спектрах поглощения флуореноноазакраунофанов наблюдаются полосы поглощения в видимой и ультрафиолетовой областях характерные для 2,7-дизамещенных флуоренонов. ${ }^{[27,28]}$

\section{Выводы}

В заключение отметим, что нами получены и охарактеризованы первые представители нового семейства азациклофанов - флуореноноазакраунофаны и флуоренонокриптанд, которые потенциально являются рецепторами катионов металлов и органических молекул. Комплексообразующие свойства этих соединений сейчас исследуются.

\section{Список литературы}

\section{References}

1. Inokuma S., Sakaki S., Nishimura J. Top. Curr. Chem. 1994, 172, 87-118.
2. Tsuzuki S., Houjou H., Nagawa Y., Goto M., Hiratani K. J. Am. Chem. Soc. 2001, 123, 4255-4258.

3. Fis M.J., Seiler P., Muslinkina L.A., Badertscher M., Pretsch E., Diederich F., Alvarado R., Echegoyen L., Nunez I.P. Helv. Chim. Acta. 2002, 85, 2009-2055.

4. Xu J., Lai Y.-H., Wang W. Org. Lett. 2003, 5, 2181-2184.

5. Müller-Dethlefs K., Hobza P. Chem. Rev., 2000, 100, 143-168.

6. Bradshaw J.S., Krakowiak K.E., Izatt R.M. Chemistry of Heterocyclic Compounds: Aza-Crown Macrocycles. Wiley \& Sons, New York, 1993, 51, 885 p.

7. Hartley J.H., James T.D., Ward C.J. J. Chem. Soc., Perkin 1. 2000, 3155.

8. Ma J.C., Dougherty D.A. Chem. Rev. 1997, 97, 1303-1324.

9. Gokel G. W., De Wall S. L., Meadows E. S. Eur. J. Org. Chem. 2000, 2967-2978.

10. De Wall S.L., Meadows E.S., Barbour L.J., Gokel G.W. Proc. Natl. Acad. Sci. USA 2000, 97, 6271-6276.

11. Barbour L.J., De Wall S.L., Meadows E.S., Gokel G.W. Ind. Eng. Chem. Res. 2000, 39, 3436-3441.

12. Gokel G.W., Barbour L.J., Ferdani R., Hu J. Acc. Chem. Res. 2002, 35, 878-886.

13. Hunter C.A., Lawson K.R., Perkins J., Urch J. J. Chem. Soc. Perkin Trans. 2. 2001, 651-669.

14. Jennings W.B., Farrell B.M., Malone J.F. Acc. Chem. Res. 2001, 34, 885-894.

15. Desiraju G.R. Acc. Chem. Res. 2002, 35, 565-573.

16. Meyer E.A., Castellano R.K., Diederich F. Angew. Chem. 2003, 115, 1244-1287.

17. Hubin T.J., Busch D.H. Coord. Chem. Rev. 2000, 200-202, 5-52.

18. Grieg L.M., Philp D. Chem. Soc. Rev. 2001, 30, 287-302.

19. Cantrill S.J. Fulton D.A., Heiss A.M., Pease A.R., Stoddart J.F., White A.J.P., Williams D.J. Chem. Eur. J. 2000, 6, 2274-2287.

20. Lukyanenko N.G., Lyapunov A.Yu., Kirichenko T.I., Botoshansky M.M., Simonov Yu.A., Fonari M.S. Tetrahedron Lett. 2005, 46, 2109-2112.

21. Lukyanenko N.G., Kirichenko T.I., Lyapunov A.Yu., Kulygina C.Yu., Simonov Yu.A., Fonari M.S., Botoshansky M.M. Tetrahedron Lett. 2004, 45, 2927-2930.

22. Lukyanenko N.G., Kirichenko T.I., Lyapunov A.Yu., Mazepa A.V., Simonov Yu.A., Fonari M.S., Botoshansky M.M. Chem. Eur. J. 2005, 11, 262-270.

23. Simonov Yu.A., Bogaschenko T.Yu., Pastushok V.N., Botoshansky M.M., Fonar' M.S., Lyapunov A.Yu., Luk'yanenko N.G. Russ. J. Org. Chem. 2006, 42, 1075-1082.

24. Lukyanenko N.G., Kirichenko T.I., Lyapunov A.Yu., Bogaschenko T.Yu., Pastushok V.N., Simonov Yu.A., Fonari M.S., Botoshansky M.M. Tetrahedron Lett. 2003, 44, 7373-7376.

25. Lukyanenko N.G., Lyapunov A.Yu., Kirichenko T.I. Russ. Chem. Bull., Int. Ed. 2007, 56, 986-992.

26. Luk'yanenko N.G ., Kirichenko T.I., Lyapunov A.Yu., Kulygina E.Yu., Mazepa A.V. Russ. J. Org. Chem. 2009, 45, 304-311.

27. Haenel M.W., Irngartinger H., Krieger C. Chem. Ber. 1985, $118,144-162$.

28. Schweitzer D., Haenel M. W. Chem. Ber. 1985, 118, 163-175. 